\title{
Revista Brasileira de Medicina de Família e Comunidade em 2014
}

\author{
Brazilian Journal of Family and Community Medicine in 2014 \\ Revista Brasileña de Medicina Familiar y Comunitaria en 2014
}

Michael Schmidt Duncan. Secretaria Municipal de Saúde do Rio de Janeiro. Rio de Janeiro, RJ, Brasil. Msduncan81@gmail.com (Autor correspondente) Leonardo Ferreira Fontenelle. Universidade Federal de Pelotas (UFPel). Pelotas, RS, Brasil. leonardo@leonardof.med.br

Armando Henrique Norman. Durham University, Anthropology Department. Durham, UK. ahnorman@hotmail.com

Com este número 33, concluímos o ano de 2014, que marcou os 10 anos da Revista Brasileira de Medicina de Família e Comunidade (RBMFC). Em 5 de dezembro comemoramos o dia do Médico de Família e Comunidade (MFC), e, portanto, escolhemos como foto de capa a foto vencedora do concurso \#OrgulhodeSerMFC.

Os artigos deste número refletem os dois eixos centrais da revista: os aspectos clínicos da MFC e o campo interdisciplinar da Atenção Primária à Saúde (APS). Os artigos originais abordam temas como trabalho com agentes comunitários de saúde (ACS), percepção de um grupo de gestantes sobre mortalidade infantil, percepção de homens idosos sobre saúde e serviços de saúde e óbitos por acidentes de trânsito. Os dois relatos de experiência descrevem um grupo de abordagem do tabagismo e o programa teórico de núcleo de um importante e tradicional programa de residência de Medicina de Família e Comunidade. O caso clínico relata a abordagem na APS de dois casos de esclerose múltipla, que é uma doença de difícil diagnóstico, com manifestaçóes iniciais bastante inespecíficas. $\mathrm{O}$ artigo de revisão aborda os bancos de leite humano, que cumprem importante papel na promoção do aleitamento materno, porém são geralmente pouco abordados nas consultas de pré-natal e puericultura. Apresentamos também uma entrevista com a médica de família e comunidade espanhola Pilar Astier, que fala sobre a APS na Espanha. Dentro da linha de publicar documentos importantes da Sociedade Brasileira de Medicina de Família e Comunidade, estamos publicando o "Manifesto de Curitiba: pela Prevenção Quaternária e por uma Medicina sem conflitos de interesses”, fruto do I Seminário Brasileiro de Prevenção Quaternária, que ocorreu em Curitiba em novembro do ano passado.

A partir do número anterior (32), Michael Schmidt Duncan, que já era editor de artigos de revisão clínica, e Leonardo Ferreira Fontenelle, que já atuava como revisor na avaliação por pares, se juntaram a Armando Henrique Norman como editores-chefes, e Melissa Moura Mello entrou no lugar de Josane Norman como editora adjunta, coordenando o fluxo dos manuscritos na plataforma e realizando a revisão textual.

Em 2014, publicamos 63 artigos, sendo 21 artigos originais, que relatam achados de pesquisa relevantes para a Medicina de Família e Comunidade ou para o campo da Atenção Primária à Saúde. Demos continuidade à política de seguir publicando também artigos de revisão, casos clínicos e relatos de experiência. Publicamos também quatro documentos importantes da Sociedade Brasileira de Medicina de Família e Comunidade, incluindo o documento sobre Prevenção Quaternária do número atual. Ainda sobre o tema da Prevenção Quaternária, publicamos no segundo trimestre deste ano uma série de artigos de debate com uma visão crítica sobre a obrigatoriedade do rastreamento de câncer de mama no Uruguai.

Inauguramos duas seçôes novas, que pretendemos tornar permanentes: artigos de revisão clínica e entrevistas. Também demos início a uma série especial de artigos sobre formação em Medicina de Família e Comunidade em outros países. Outra novidade em 2014 foi introduzir uma avaliação padronizada de metodologia quantitativa por um de nossos editores (Leonardo Fontenelle) para todos os artigos com esse perfil, após a primeira avaliação por pares. Essas iniciativas têm como objetivo qualificar os artigos publicados e aproximar cada vez mais a RBMFC do público alvo da revista. 
Tivemos um aumento no número de artigos submetidos na plataforma (132 até início de dezembro deste ano vs. 101 durante todo o ano de 2013). Para contornar o aumento no tempo de revisão decorrente disso e também com o objetivo de qualificar o processo de avaliação editorial e por pares, estamos introduzindo novos editores associados, que passarão a atuar mais ativamente a partir de 2015.

Outra novidade que estamos preparando para o ano de 2015 é a publicação de um número especial dedicado à Prevenção Quaternária, organizado pelo médico de família e comunidade belga que cunhou o termo Prevenção Quaternária, Marc Jamoulle, e pelo nosso editor Armando Henrique Norman. Esse número especial terá forte participaçáo internacional e esperamos que seja um marco na discussão teórica sobre esse tema.

Gostaríamos de agradecer os leitores, que têm apoiado o crescimento da revista, bem como o trabalho incansável dos avaliadores, fundamental para garantirmos a qualidade dos artigos publicados. Por fim, parabenizamos os leitores médicos de família e comunidade pelo seu dia e desejamos a todos um feliz natal e um próspero ano novo.

Michael Schmidt Duncan

Leonardo Ferreira Fontenelle

Armando Henrique Norman

Editores 